\title{
A call for research on soft tissue manipulation (STM) as a bone anabolic therapy
}

\author{
Aric Anloague ${ }^{1,4}$, Devanshi Patel ${ }^{1,4}$, Stephanie Henderson ${ }^{1,4}$, Hillary Rolfs ${ }^{1,4}$, Mackenzie Powell ${ }^{1,4}$, Sunny B Pate $\left.\right|^{2,4}$, \\ Nicole M LaFave ${ }^{1,4}$, Vincent R Marshall ${ }^{1,4}$, Bryan G Wacker ${ }^{1,4}$, Collin M Young ${ }^{1,4}$, Julia M Hum ${ }^{3,4}$, Kevin Gries ${ }^{3,4,5}$, \\ Jonathan W Lowery ${ }^{3,4 *}$ \\ 'Marian University College of Osteopathic Medicine, 3200 Cold Spring Road, Indianapolis, Indiana, USA 46222 \\ ${ }^{2}$ William Carey University College of Osteopathic Medicine, 710 William Carey Parkway, Hattiesburg, Mississippi, USA 39401 \\ ${ }^{3}$ Division of Biomedical Science, Marian University College of Osteopathic Medicine, 3200 Cold Spring Road, Indianapolis, Indiana, USA 46222 \\ ${ }^{4}$ Bone \& Muscle Research Group, Marian University, 3200 Cold Spring Road, Indianapolis, Indiana, USA 46222 \\ ${ }^{5}$ Program in Exercise \& Sports Science, Marian University, 3200 Cold Spring Road, Indianapolis, Indiana, USA 46222
}

\section{Article Info}

\section{Article Notes}

Received: June 02, 2021

Accepted: July 06, 2021

\section{*Correspondence:}

Jonathan W. Lowery, Associate Professor of Physiology, Marian University College of Osteopathic Medicine, 3200 Cold Spring

Road, Indianapolis, Indiana, USA 46222.

Email: jlowery@marian.edu

${ }^{\circ} 2021$ Jonathan W Lowery. This article is distributed under the terms of the Creative Commons Attribution 4.0 International License.

\section{Keywords:}

Soft tissue manipulation

inflammation

bone

manual therapy

IL-6, mechanotransduction

\section{Abstract}

Individuals with osteoporosis, i.e., low bone mass, are at enhanced risk for fracture, disability, and death. Hospitalizations for osteoporotic fractures exceed those for heart attack, stroke, and breast cancer. Osteoporosis rates are predicted to increase due to an aging global population yet there are limited pharmacological treatment options for osteoporosis, particularly for longterm management of this chronic condition. Moreover, the drug development pipeline is relatively bereft of new strategies and drug candidates, creating an urgent need for developing new therapeutic strategies for treating osteoporosis. In this mini-review, we speculate about the potential for noninvasive soft tissue manipulation (STM) to exert anabolic effects on the skeleton that may provide therapeutic benefit for individuals with low bone mass. Our rationale is premised on work by us and others showing that STM leads to decreased levels of chemokines and pro-inflammatory cytokines (such as Interleukin (IL)-3, IL-6, and IL-8) known to restrict the differentiation and/or activity of bone-forming osteoblasts. However, there are no published studies examining whether STM impacts bone mass, potentially limiting the widespread use of this non-invasive and non-pharmacological intervention in the worldwide treatment of patients with osteoporosis, individuals with low bone mass due to being bed-ridden or otherwise mobility-limited, and persons subjected to spaceflight-related bone loss.

\section{Introduction}

Bone mass in humans generally begins to decline after age thirty due to the rate of bone resorption exceeding the rate of bone formation ${ }^{1}$. Osteoporosis is a chronic disease of low bone mass that places individuals at enhanced risk for fracture, disability, and death $^{2}$. According to the United States (US) Centers for Disease Control \& Prevention, more than 10 million individuals have osteoporosis - the majority of whom are over the age of fifty years ${ }^{3}$. In the US, hospitalizations for osteoporotic fractures exceeds those for heart attack, stroke, and breast cancer ${ }^{4}$. It has been estimated that by 2025 the number of fractures due to osteoporosis will increase to nearly three million in the US alone, creating a $\$ 25$ billion financial burden ${ }^{5}$. Given the relationship between bone mass and osteoporosis - i.e., "an increase of [bone mass] by one standard deviation would reduce the fracture risk by $50 \%{ }^{6 \prime}-$ therapies aimed at increasing bone mass are crucial for adequate management of this disease. 
A

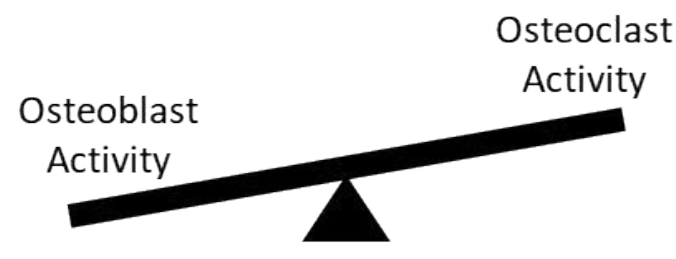

Bone mass accrual
B

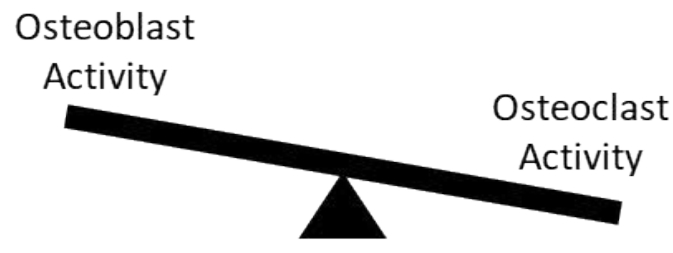

Bone mass loss

Figure 1. Schematic representation of the relationship between bone formation and bone resorption. Gains in bone mass (A) may occur by i) increasing osteoblast activity, ii) decreasing osteoclast activity, or iii) doing both. Conversely, bone loss (B) may occur by i) increasing osteoclast activity, ii) decreasing osteoblast activity, or iii) doing both.

The primary pharmacological treatment goal for osteoporosis is reducing fracture risk by stabilizing or increasing bone mass by taking advantage of the fact that the skeletal system is exquisitely capable of resorbing existing bone matrix (via the action of osteoclasts) and forming new bone matrix (via the action of osteoblasts). The balance of these two processes, which may be envisioned as a see-saw relationship (Figure 1), determines whether bone mass will be accrued or lost. The most common treatment for osteoporosis is anti-resorptive agents which are generally effective at inhibiting osteoclast function $^{7}$ but have important contraindications and a drug holiday is recommended after five years of treatment due to risk of adverse events ${ }^{8,9}$. An additional drawback of anti-resorptive therapies is that they generally do not increase bone formation but merely slow the rate of bone resorption. Some patients, particularly those with very high fracture risk, require an anabolic therapy instead ${ }^{7}$ and, in the US, there are three bone-anabolic drugs approved for osteoporosis treatment: teriparatide and the related abaloparatide, both of which activate the Parathyroid Hormone signaling pathway, and romosozumab, which is a neutralizing antibody against the Wnt pathway antagonist Sclerostin. Each typically lead to robust gains in bone mass but have important limitations including significant cost and, for some agents, a limited window of treatment, necessitating switching to an anti-resorptive medication to avoid a notable rebound in bone resorption after withdrawal of anabolic therapy ${ }^{10,11}$.

Thus, despite the fact that osteoporosis rates are expected to rise significantly in the coming decades ${ }^{12}$, there are limited long-term pharmacological treatment options. Unfortunately, there are few candidates in the drug development pipeline and several promising candidate therapies with novel mechanisms of action, while effective at improving bone mass and reducing fracture incidence, have been associated with significant adverse events in clinical trials ${ }^{13}, 14$. Some adverse events were found significant enough to pull seemingly promising drugs out of development, as in the example of the cathepsin
$\mathrm{K}$ inhibitor odanacatib. Consequently, there is an urgent need for developing new strategies and targets for treating osteoporosis. That said, we recently reported that there is a striking lack of heterogeneity of study within the bone remodeling field - with just three molecular pathways (transforming growth factor-beta (TGF- $\beta$ ) superfamily, mitogen-activated protein (MAP) kinase, and Wnt) accounting for the majority of publications and nearly half of funded NIH grants during the prior ten years ${ }^{15}$.

Inflammation, bone loss, and soft tissue manipulation

Inflammation is a potent driver of bone loss through impairing bone formation and promoting bone resorption $^{16-19}$. For instance, the pro-inflammatory cytokine Interleukin (IL)-6 restricts osteoblast differentiation, while promoting osteoclast differentiation, and decreasing IL-6 activity in vivo promotes bone mass accrual ${ }^{20,21}$. Moreover, IL-6 deficient mice are protected from bone loss in a model of post-menopausal osteoporosis ${ }^{22}$. Thus, developing strategies to reduce IL-6-mediated inflammation in patients with low bone mass is an important goal.

Soft tissue manipulation (STM) describes a collection of non-invasive, non-pharmacological mechanotherapies (such as massage, stretch, myofascial release and counterstrain) employed by osteopathic physicians, physiotherapists and massage therapists wherein soft tissues are subjected to mechanical forces delivered by hand or by an instrument ${ }^{23}$. Cells integrate those mechanical stimuli into mechanotransductive signaling pathways that regulate cellular behavior ${ }^{23,24}$. Virtually all cells are mechanosensitive to their surrounding environment in that physical forces - e.g. stretch, compression, etc. - influence the physiology of tissues, and ultimately, the organism ${ }^{23}$. STM is used by practitioners to reduce inflammation and this idea is supported by a series of studies carried out by several investigators (including us) mimicking the STM techniques of myofascial release or counterstrain in vitro. This work demonstrates that STM-like stimulation of dermal fibroblasts, which are a mechano-sensitive cell 
type that resides in close approximation to vasculature and lymphatics and are a recipient of strain from $\mathrm{STM}^{25}$, causes numerous changes in cell biology ${ }^{26-30}$, such as reducing secretion of the pro-inflammatory cytokines IL-3, IL-6 and IL-8; inducing secretion of anti-inflammatory IL-1ra; increasing fibroblast proliferation; and reducing fibroblast apoptosis. Additionally, conditioned medium from fibroblasts subjected to STM-like stimulation promotes differentiation of satellite cells into skeletal muscle myocytes ${ }^{31}$. For certain pro-inflammatory mediators such as IL-6 and IL-8, these in vitro studies are remarkably consistent with the reduction in IL-6 or IL-8 levels observed after massage therapy in humans (soft tissue biopsies ${ }^{32}$ and plasma $^{33}$ ) and rats $\left(\right.$ sera $\left.^{34}\right)$.

\section{Call for research on using STM for treating low bone mass}

Given the connection between inflammation and bone loss, these findings lead us to hypothesize that STM may have beneficial effects on bone mass accrual. In support of this, small pilot studies in humans reported that Thai traditional massage, which is a form of STM, leads to increased serum levels of the bone formation marker $\mathrm{N}$-terminal propeptide of type 1 procollagen (P1NP) and decreased serum levels of the bone resorption marker collagen type 1 C-telopeptide (CTx) in young, healthy women as well as increased serum P1NP levels in some women with osteoporosis ${ }^{35,36}$. However, there are no published studies examining whether STM impacts bone mass - despite the fact that $>70 \%$ of osteopathic physicians report using STM (such as muscle energy or massage) in the treatment of osteoporosis ${ }^{37}$ and patients with osteoporosis self-report that STM improves quality of life, mental well-being, and health perception ${ }^{38}$. Thus, we call for investigation into the possible use of STM (particularly massage) in promoting bone anabolism using well-accepted animal models of osteoporosis (such as disuse-related atrophy or oophorectomy) and human subjects. These studies could provide evidence to support the widespread use of this non-invasive and nonpharmacological intervention in the worldwide treatment of patients with osteoporosis, individuals with low bone mass due to being bed-ridden or otherwise mobilitylimited, and persons subjected to spaceflight-related bone loss ${ }^{39}$.

\section{Acknowledgments}

The authors gratefully acknowledge critical feedback from the Marian University Bone \& Muscle Research Group and our collaborators. Funding for this work was provided by intramural award issued to JWL.

\section{References}

1. Raisz LG. Pathogenesis of osteoporosis: concepts, conflicts, and prospects. J Clin Invest. 2005;115(12):3318-25
2. Leboime A, Confavreux CB, Mehsen N, Paccou J, David C, Roux C. Osteoporosis and mortality. Joint, bone, spine : revue du rhumatisme. 2010;77 Suppl 2:S107-12.

3. Sarafrazi N, Wambogo EA, Shepherd JA. Osteoporosis or Low Bone Mass in Older Adults: United States, 2017-2018. NCHS Data Brief. 2021;(405):1-8.

4. Singer A, Exuzides A, Spangler L, O'Malley C, Colby C, Johnston K, Agodoa I, Baker J, Kagan R. Burden of illness for osteoporotic fractures compared with other serious diseases among postmenopausal women in the United States. Mayo Clin Proc. 2015;90(1):53-62.

5. Camacho PM, Petak SM, Binkley N, Clarke BL, Harris ST, Hurley DL, Kleerekoper M, Lewiecki EM, Miller PD, Narula HS, Pessah-Pollack R, Tangpricha V, Wimalawansa SJ, Watts NB. American Association of Clinical Endocrinologists and American College of Endocrinology clinical practice guidelines for the diagnosis and treatment of postmenopausal osteoporosis - 2016. Endocr Pract. 2016;22(Suppl 4):1-42.

6. Bonjour J-P, Chevalley T, Ferrari S, Rizzoli R. The importance and relevance of peak bone mass in the prevalence of osteoporosis. Salud publica de Mexico. 2009;51:s5-s17.

7. Watts NB, Bilezikian JP, Camacho PM, Greenspan SL, Harris ST, Hodgson SF, Kleerekoper M, Luckey MM, McClung MR, Pollack RP, Petak SM, Force AOT. American Association of Clinical Endocrinologists Medical Guidelines for Clinical Practice for the diagnosis and treatment of postmenopausal osteoporosis. Endocr Pract. 2010;16 Suppl 3:1-37.

8. Suresh E, Pazianas M, Abrahamsen B. Safety issues with bisphosphonate therapy for osteoporosis. Rheumatology (Oxford). 2014;53(1):19-31.

9. Qaseem A, Forciea MA, McLean RM, Denberg TD. Clinical Guidelines Committee of the American College of Physicians. Treatment of Low Bone Density or Osteoporosis to Prevent Fractures in Men and Women: A Clinical Practice Guideline Update From the American College of Physicians. Ann Intern Med. 2017;166(11):818-839.

10. Qaseem A, Forciea MA, McLean RM, Denberg TD, Physicians CGCotACo. Treatment of Low Bone Density or Osteoporosis to Prevent Fractures in Men and Women: A Clinical Practice Guideline Update From the American College of Physicians. Ann Intern Med. 2017;166(11):818839.

11. Kerschan-Schindl K. Romosozumab: a novel bone anabolic treatment option for osteoporosis? Wien Med Wochenschr. 2019.

12. Gullberg B, Johnell O, Kanis JA. World-wide projections for hip fracture. Osteoporosis international : a journal established as result of cooperation between the European Foundation for Osteoporosis and the National Osteoporosis Foundation of the USA. 1997;7(5):407-13.

13. Bill Berkrot BH. Heart safety clouds hopes for Amgen, UCB bone drug approval 2017. https://www.reuters.com/article/us-amgen-ucbosteoporosis/heart-safety-clouds-hopes-for-amgen-ucb-bone-drugapproval-idUSKBN18H14L.

14. Mullard A. Merck \&Co. drops osteoporosis drug odanacatib. Nat Rev Drug Discov. 2016;15(10):669.

15. Shadmand M, Jackson K, Bender C, Donnelly S, Guan H, Tobin K, Yates S, Hum J, Lowery JW. Bringing Attention to Lesser-known Bone Remodeling Pathways. Clinical reviews in bone and mineral metabolism. 2018;16(3):95-102.

16. Straub RH, Cutolo M, Pacifici R. Evolutionary medicine and bone loss in chronic inflammatory diseases--A theory of inflammation-related osteopenia. Semin Arthritis Rheum. 2015;45(2):220-8.

17. Lacativa PG, Farias ML. Osteoporosis and inflammation. Arq Bras Endocrinol Metabol. 2010;54(2):123-32. 
18. Pietschmann P, Mechtcheriakova D, Meshcheryakova A, FogerSamwald U, Ellinger I. Immunology of Osteoporosis: A Mini-Review. Gerontology. 2016;62(2):128-37.

19. Agrawal M, Arora S, Li J, Rahmani R, Sun L, Steinlauf AF, Mechanick JI, Zaidi M. Bone, inflammation, and inflammatory bowel disease. Curr Osteoporos Rep. 2011; 9(4):251-7.

20. Kaneshiro S, Ebina K, Shi K, Higuchi C, Hirao M, Okamoto M, Koizumi $\mathrm{K}$, Morimoto T, Yoshikawa $\mathrm{H}$, Hashimoto J. IL-6 negatively regulates osteoblast differentiation through the SHP2/MEK2 and SHP2/ Akt2 pathways in vitro. Journal of bone and mineral metabolism. 2014;32(4):378-92.

21. Murakami M, Nishimoto N. [IL-6 inhibitors prevent bone loss and cartilage degeneration in rheumatoid arthritis]. Clin Calcium. 2015;25(12):1851-7.

22. Poli V, Balena R, Fattori E, Markatos A, Yamamoto $M$, Tanaka $H$ Ciliberto G, Rodan GA, Costantini F. Interleukin-6 deficient mice are protected from bone loss caused by estrogen depletion. Embo J. 1994;13(5):1189-96.

23. Loghmani MT, Whitted M. Soft Tissue Manipulation: A Powerful Form of Mechanotherapy. Journal of Physiotherapy \& Physical Rehabilitation. 2016;1:122.

24. Thompson WR, Scott A, Loghmani MT, Ward SR, Warden SJ Understanding Mechanobiology: Physical Therapists as a Force in Mechanotherapy and Musculoskeletal Regenerative Rehabilitation. Phys Ther. 2016;96(4):560-9.

25. Zein-Hammoud M, Standley PR. Modeled Osteopathic Manipulative Treatments: A Review of Their in Vitro Effects on Fibroblast Tissue Preparations. The Journal of the American Osteopathic Association. 2015;115(8):490-502

26. Meltzer KR, Standley PR. Modeled repetitive motion strain and indirect osteopathic manipulative techniques in regulation of human fibroblast proliferation and interleukin secretion. The Journal of the American Osteopathic Association. 2007;107(12):527-36.

27. Eagan TS, Meltzer KR, Standley PR. Importance of strain direction in regulating human fibroblast proliferation and cytokine secretion: a useful in vitro model for soft tissue injury and manual medicine treatments. J Manipulative Physiol Ther 2007;30(8):584-92.

28. Standley PR, Meltzer K. In vitro modeling of repetitive motion strain and manual medicine treatments: potential roles for pro- and antiinflammatory cytokines. J Bodyw Mov Ther. 2008;12(3):201-3.
29. Meltzer KR, Cao TV, Schad JF, King H, Stoll ST, Standley PR. In vitro modeling of repetitive motion injury and myofascial release. J Bodyw Mov Ther. 2010;14(2):162-71.

30. Anloague A, Mahoney A, Ogunbekun O, Hiland TA, Thompson WR, Larsen B, Loghmani MT, Hum JM, Lowery JW. Mechanical stimulation of human dermal fibroblasts regulates pro-inflammatory cytokines: potential insight into soft tissue manual therapies. BMC Res Notes. 2020;13(1):400.

31. Hicks MR, Cao TV, Campbell DH, Standley PR. Mechanical strain applied to human fibroblasts differentially regulates skeletal myoblast differentiation. J Appl Physiol (1985). 2012;113(3):465-72.

32. Crane JD, Ogborn DI, Cupido C, Melov S, Hubbard A, Bourgeois JM, Tarnopolsky MA. Massage therapy attenuates inflammatory signaling after exercise-induced muscle damage. Science translational medicine. 2012;4(119):119ra13.

33. White GE, West SL, Caterini JE, Di Battista AP, Rhind SG, Wells GD. Massage Therapy Modulates Inflammatory Mediators Following Sprint Exercise in Healthy Male Athletes. J Funct Morphol Kinesiol. 2020;5(1).

34. Loghmani MT, Tobin C, Quigley C, Fennimore A. Soft Tissue Manipulation May Attenuate Inflammation, Modulate Pain, and Improve Gait in Conscious Rodents With Induced Low Back Pain. Military Medicine. 2021;186(Supplement_1):506-514.

35. Saetung S, Chailurkit LO, Ongphiphadhanakul B. Thai traditional massage increases biochemical markers of bone formation in postmenopausal women: a randomized crossover trial. BMC Complement Altern Med. 2013;13:69.

36. Saetung S, Chailurkit LO, Ongphiphadhanakul B. Acute changes in biochemical markers of bone resorption and formation after Thai traditional massage. J Med Assoc Thai. 2010;93(7):771-5.

37. Channell MK, Wang Y, McLaughlin MH, Ciesielski J, Pomerantz SC. Osteopathic Manipulative Treatment for Older Patients: A National Survey of Osteopathic Physicians. The Journal of the American Osteopathic Association. 2016;116(3):136-43.

38. Papa L, Mandara A, Bottali M, Gulisano V, Orfei S. A randomized control trial on the effectiveness of osteopathic manipulative treatment in reducing pain and improving the quality of life in elderly patients affected by osteoporosis. Clinical cases in mineral and bone metabolism: the official journal of the Italian Society of Osteoporosis, Mineral Metabolism, and Skeletal Diseases. 2012;9(3):179-83.

39. Morey-Holton ER, Globus RK. Hindlimb unloading rodent model: technical aspects. J Appl Physiol (1985). 2002;92(4):1367-77. 